\title{
Proceeding
}

Supplementary Issue: Winter Conferences of Sports Science. Costa Blanca Sports Science Events, 22-23 March 2021. Alicante, Spain.

\section{Students' physical and mental disorders: How to avoid victim behavior through exercise and sport}

\author{
NADEZHDA YU KOSTYUNINA ${ }^{1}$, LILIIA A. LATYPOVA², NATALYA N. KALATSKAYA ${ }^{1}$, MARINELA I. \\ GRUDEVA ${ }^{3}$ \\ ${ }^{1}$ Institute of Psychology and Education, Kazan (Volga Region) Federal University, Kazan, Russian Federation \\ 2Institute of Management, Economics and Finance, Kazan (Volga Region) Federal University, Kazan, Russian Federation \\ ${ }^{3}$ Department of Speech Therapy and Medical Pedagogy, "Prof. Dr. Paraskev Stoyanov" Medical University, Varna, Bulgaria
}

\begin{abstract}
The object of this paper is to study the negative impact of Internet sites on the psyche of young people, to identify the facts of unsafe use of the Internet by students leading to the development of cyber addiction and victim behavior. The article is aimed at studying the propensity for victim behavior among University students in Russia and Bulgaria and developing recommendations to shape the information security of students on the Internet in order to help reduce victim behavior. The methods of the research are: theoretical (study and analysis of psychological, pedagogical, and methodological literature on the research problem; analysis, synthesis, and generalization of empirical data; causal analysis of pedagogical experience data); empirical (questionnaire, testing, survey); methods of qualitative interpretation and data processing. The authors outlined three stages of creating a safe educational environment to prevent and correct victim behavior of students on the Internet - organizational, practical, and generalizing. The results of the research show that serious, systematic, substantial preventive and corrective work is needed to reduce student victimization, cyber addiction, and the formation of information security for students on the Internet. Teaching students to carefully perceive and critically evaluate information is one of the possible ways to create safe behavior on the Web, since ignorance of the rules of work and communication leads to rash, risky, frivolous actions on the Internet. The outlined in the research three stages of creating a safe educational environment can be used by university teachers, educational psychologists, psychologists of the rehabilitation centers and psychological and pedagogical assistance centers for prevention and correction victim behavior of students on the Internet. The data obtained and their analysis help identify students with an increased victimization background and predict their personal development, organization of prevention processes and correction of victim student behavior in the Internet. The results can be useful when developing programs for safe use of content and online sites by adolescents and youth. Keywords: Practices; Sports; Physical disorders; Mental disorders; Internet threats; Information security; Prohibited information; Victim behavior on the internet; Internet addiction.
\end{abstract}

Cite this article as:

Kostyunina, N.Y., Latypova, L.A., Kalatskaya, N.A., \& Grudeva, M.I. (2021). Students' physical and mental disorders: How to avoid victim behavior through exercise and sport. Journal of Human Sport and Exercise, 16(3proc), S1216-S1226. https://doi.org/10.14198/jhse.2021.16.Proc3.38

Corresponding author. Institute of Psychology and Education, Kazan (Volga Region) Federal University, Kazan, Russian Federation.

E-mail: garifullin@mail.ru

Abstract submitted to: Winter Conferences of Sports Science. Costa Blanca Sports Science Events, 22-23 March 2021. Alicante, Spain.

JOURNAL OF HUMAN SPORT \& EXERCISE ISSN 1988-5202.

(c) Faculty of Education. University of Alicante.

doi:10.14198/jhse.2021.16.Proc3.38

S1216 | 2021| Proc3| VOLUME 16

(C) 2021 University of Alicante 


\section{INTRODUCTION}

The present-day life of young people is inconceivable without and outside the Internet, since it is the Internet that helps them improve intellectual and professional level and satisfy cultural and vital needs according to their inclinations and interests (Shinkevich et al., 2020).

Educational portals, youth network communities and communication groups emerge thanks to the Internet. Playing an important role in the life of modern students the Internet has a serious impact on individual behavior, social and cognitive activity, value orientations, and leisure.

The importance of information technology in the life of society has been the topic of many scientific papers. The influence of the internet and the "immersion" of a person in the virtual world is now the area of focus of the Russian and international scientific communities. Having studied the problem of the Internet's impact we present some statistics on the spread of the Internet noting its positive and negative sides.

1. In analysts' reports as of January 1,2019 , the number of Internet users in the world amounted to $4,100,667,287$. To compare, in 2016 this figure was 3.42 billion users.

2. The largest number of Internet users in Asia is $49 \%$ of the total. The second place is taken by Europe with $16.8 \%$ of users, followed by Africa (11\%) and the Caribbean (10.4\%). $12.8 \%$ of Internet users are unevenly distributed around the world.

3. Google processes more than 7 billion search queries worldwide per day: sometimes this figure reaches 10 billion. $15 \%$ of these queries have never been searched on Google before.

4. More than 4 million posts on personal blogs are published on the Internet daily: $1 / 3$ of them are published on sites, the rest of them are posted in social networks.

5. According to analysts, in 2021the number of social network users in the world will amount to 2.77 billion compared to 2.46 billion in 2017.

6. On average, people spend 2 hours 15 minutes in social networks daily.

7. Facebook Messenger and WhatsApp are the most popular messaging apps, with over $50 \%$ of Internet users using both.

8. $39 \%$ of cyber-attacks are carried out for financial gain or secret data access, 4000 ransomware attacks occur every day.

9. The amount of damage caused by cybercrime by 2021 is expected to be $\$ 6$ trillion a year, compared to $\$ 3$ trillion in 2019. P. Krapp (= 2005) introduces the concept of hacktivism (a portmanteau of hack and activism in English) - the use of computers and computer networks illegally to promote political ideas, freedom of speech, protection of human rights and freedom of information. Over time, the concept received a dual interpretation. Hacktivism can mean both computer terrorism and socially oriented hacking, as explained by P. Krapp (2011). According to the Federal Service for Technical and Expert Control, cyber terrorism is a complex of illegal actions in cyberspace that pose a threat to state security, the individual and society. It may lead to damage to material objects, distortion of information and other problems. The main goal of cyber 
terrorism is to influence the solution of social, economic, and political problems, while the goal of hacking is making changes to the software to achieve certain goals that differ from the goals of the creators of the programs, very often the changes are malicious. The average amount demanded by hackers after the attack is $\$ 1,077$.

10. Attacks of ransomware viruses decreased by almost $30 \%$ in 2019 , and the number of infections with crypto miners increased by $44.5 \%$. Crypto miners are special programs that use powerful infected devices for digital money fraud in the interests of attackers.

11. $53 \%$ of users access the Internet from mobile devices. In 2018 , mobile traffic accounted for $48.2 \%$ (Statistics, 2019).

The authors share the view of T.V. Bogacheva (2014) and V.A. Taburtsa (2016) who note that the insecure use of the Internet can cause psychosocial harm to adolescents and youth, physical and mental disorders, formation of social deviations, and, because of their manifestations, mistreatment of people, suicidal tendencies, disordered communication, development of cyber addiction.

\section{Review of literature}

Now, the problem of information security is the most topical one in the world community and has been on the agenda for many years. Information Security (or InfoSec) is the security of information and supporting infrastructure from accidental or intentional influences of natural or artificial kind that could cause unsustainable damage to the subjects of information relations, including owners and users of information and supporting infrastructure (Makarenko, 2009). The main objective of information security is the balanced protection of confidentiality, integrity, and availability of data.

Children's information security is a state of children's security in which there is no risk associated with causing harm to children's physical, mental, spiritual, and moral development and health by information, the Internet included (Federal Law, 2010).

When implementing a set of measures aimed at ensuring the safety of youth on the Internet, it is necessary to take into account international practice, namely Articles 13,17, 34 of the "Convention on the Rights of the Child" of the UN General Assembly, which oblige States parties to ensure the development of "appropriate principles for protecting the child from information and materials harmful to his well-being" (Child Safety Online, 2019).

The European Court of Human Rights recognized the protection of morality in a democratic society as the legitimate aim of restricting freedom of expression, in accordance with part 2 of Article 10 of the European Convention on Human Rights and noted that states have the right to adopt laws restricting the dissemination of information and ideas, despite their advantages "as works of art or as a contribution to the public discussion of problems", including the establishment of control and classification of information products. In case of violation of the law, penalties, confiscation, and other sanctions, including criminal ones, are envisaged (Child Safety Online, 2019).

The main directions of counteracting the informational and psychological impact of the Internet generally accepted in the world community are:

1) Prohibited methods: closing servers;

2) Legal practice: criminal liability; 
3) Internet censorship;

4) Monitoring and analysis of social networks.

Recognizing the global nature of cybersecurity, Ivailo Moskovsky, Minister of Transport, Information Technology and Communications (MTITC) of Bulgaria, places most emphasis on international cooperation. Ivailo Moskovsky notes that Bulgaria maintains ties with the European Union through the European Union Agency for Cybersecurity (ENISA) and the North Atlantic Treaty Organization (NATO) on mutual understanding in the field of cybersecurity. An example of cooperation is the provision of continuous communication between Bulgaria and the Global Response Center (GRC) of the International Multilateral Partnership Against Cyber Threats (IMPACT).

In 2009, the Russia-Bulgaria International Conference "Information Cooperation and Information Security" addressed issues of counteracting the spread of illegal content on the Internet. A report by M. Tverdynin (2009), an employee of the Regional Public Center for Internet Technologies, presented a comparative analysis of preventive measures and ways to minimize victimization in Russia and Bulgaria, to which the author relates:

1) The organization of the international interaction of state and law enforcement agencies, the Internet industry, Internet users;

2) Providing the society with information on protection against illegal content;

3) Receiving individual psychological and pedagogical advisory assistance from psychologists, victimologists by victimized individuals (victims of cybercrimes);

4) Monitoring problems to improve methods of protection and conducting international Internet security problems;

5) Conducting special seminars and courses to improve the knowledge of workers in the fields of education, health, and law enforcement.

Today in Russia, the regulatory and legal framework and information security system have been formed and are still being upgraded. The Federal Law No. 114- $\$ 3$ dated July 25, 2002 "On Countering Extremist Activities" was published in Russia with the aim of counteracting such negative phenomena as extremism, xenophobia, manifestation of intolerance of various kinds, racial, national, or religious hatred associated with violence or calls to violence and prohibits the publication and distribution of printed, audio, audiovisual and other materials containing signs of extremist activity. Article 12 of the Federal Law "On Countering Extremist Activities" establishes a direct ban on the use of public communication networks for carrying out extremist activities (Federal Law, 2010).

The Federal Law of December 29, 2010, No. 436- $\$ 3$ (as amended on May 1, 2019) "On the Protection of Children from Information harmful to their health and development" (as supplemented and amended, entered into force on October 29, 2019) helps manufacturers and (or) distributors to independently determine the level of information products (or may turn to experts). The changes affected not only television programs, but also sites on the information and telecommunication network of the Internet (Federal Law, 2010).

To improve the state security system on the Internet in Russia, regulatory legal acts are developed and adopted. For 2018-2020, the Ministry of Telecommunications and Communications has prepared an action plan for "the Concept of Information Security for Children in the Russian Federation", which involves the implementation of activities where the goal is to increase the level of media literacy among adolescents and youth. In 2020, in Russia, the state program "Digital Economy" will put forward a system of filtering Internet traffic to protect adolescents and youth from dangerous and negative content (Roskomsvoboda, 2020). 
Deviation from the norms of safe behavior on the Web, implemented in social, mental, and moral manifestations of a personality, most frequently causes University students' victim behavior on the Internet. The age period of students is especially important for studying the problem of victimization on the Internet for several reasons: they form one of the largest groups of Internet users; students are more independent and autonomous than, for example, adolescents; at the same time, the significance of this age period is not as great as in sensitive periods, however, personality formation has not yet been completed, and any negative risks can affect the harmonious development of a young person and lead to deviant victimization.

As a rule, victims of cyber victimization are young people with a low level of self-esteem, life satisfaction and academic achievement, a high level of personal victimization. They consume psychotropics and are prone to depression, aggression, anxiety, and loneliness (Kowalski et al., 2014).

According to N. Yu. Kostyunina et al. (2018), victim behavior on the Internet is understood as a deviation from the norms of safe behavior due to the personality traits of students (riskiness, impulsivity, recklessness, etc.) and deformation of the value-motivational component of the personality (first of all, by the deprivation of security needs), as a result of which the person gains a high predisposition to become an addict and a victim of crimes on the Internet (Kostyunina et al., 2018).

\section{Purpose of the study}

The aim of the research is to study the propensity for victim behavior among students in Russia and Bulgaria, to give recommendations on the formation of information security for students on the Internet to help reduce victimity of a personality.

The following diagnostic tools were implemented: A.M. Schubert's (2019) "Readiness for Risk" technique (2019), O.O. Andronnikova's technique "Propensity for victim behavior" and A.V. Toncheva's (2012) questionnaire to detect the level of cyber-communication addiction. The research involved 120 first- and second-year students at Medical University "Prof. Dr. Paraskev Stoyanov" (Varna, Bulgaria) and 114 firstand second-year students at Kazan Federal University (KFU) (Kazan, Russia).

\section{MATERIALS AND METHODS}

\section{Participants}

The research involved 120 first- and second-year students at Medical University "Prof. Dr. Paraskev Stoyanov" (Varna, Bulgaria) (group 1- G1) and114 first- and second-year students at Kazan Federal University (KFU) (Kazan, Russia)(group 2- G2).

\section{Methods}

In accordance with the aim of the research, the following research methods were used:

1) Theoretical: the study and analysis of psychological, pedagogical, and methodological literature on the research problem; analysis, synthesis, and generalization of empirical data; causal analysis of pedagogical experience data;

2) Empirical: questionnaire, testing, survey;

3) Methods of qualitative interpretation and data processing.

\section{Diagnostic tools}

The following diagnostic tools were implemented: 
1) Schubert's "Readiness for Risk" technique (Schubert, 2019). As a result of the diagnosis, we revealed that it is the internal factors and motives that determine the readiness for risk of the individual. It is only a high assessment of one's own capabilities and efforts that can help a person subjectively evaluate a situation for oneself as less risky, not a victim one than it seems to an outside observer. We also note that readiness for risk is a property of personal self-regulation that a person shows when making decisions and choosing strategies for behavior in the face of uncertainty. Such conditions of uncertainty on the Web are quite frequent.

2) Andronnikova's technique "Propensity for victim behavior" (Andronnikova, 2005; Andronnikova, 2009). The technique helps determine the level of potential and realized victimity as a personality trait and realize that the victimization on the Internet is attributable to the actions of a person that provoke the desire of others to attack. Most often, such behavior manifests itself unconsciously, or spontaneously. It unfolds in such a way that external circumstances, the actions of other people turn out to be harmful to this individual. Persons at risk of becoming a victim exhibit different types of victim behavior, ranging from actively provoking aggressors against themselves to passive submission to violence and the manifestation of an absolute misunderstanding of the danger of the situation and ignoring basic safety standards.

3) Toncheva's questionnaire to detect the level of cyber-communication addiction (Toncheva, 2012). The study on the questionnaire helps understand the level of dependence on communication in social networks, forums, chats, group games that can ultimately lead to the replacement of family members and friends in real life with virtual ones.

\section{RESULTS}

To study the peculiarities of human behavioral reactions in situations involving uncertainty, danger to life, requiring violation of established norms, rules, we used Schubert's "Readiness for Risk" technique (Figure 1). We found out that $52.5 \%$ of students of the first group and $41.2 \%$ of the second group are too cautious or careful about risk.

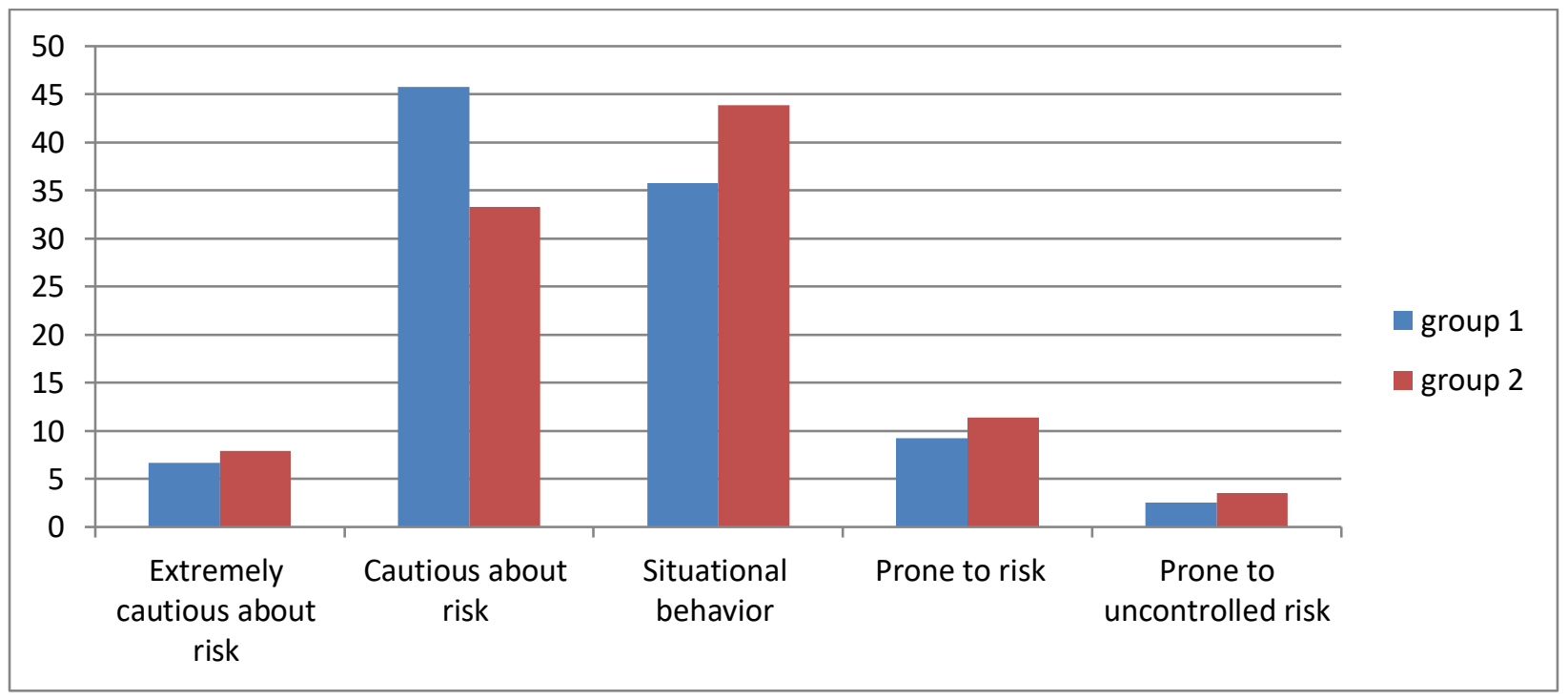

Figure 1. Students' diagnostic results on Schubert's "Readiness for Risk" technique. 
A risk appetite was shown by $9.2 \%$ of students from Bulgaria and $11.4 \%$ of students from Russia. $2.5 \%$ of respondents in the first group and $3.5 \%$ of students in the second group are prone to uncontrolled risk (no significant statistical differences were found).Students' diagnostic results on Toncheva's questionnaire are presented in Figure 2.

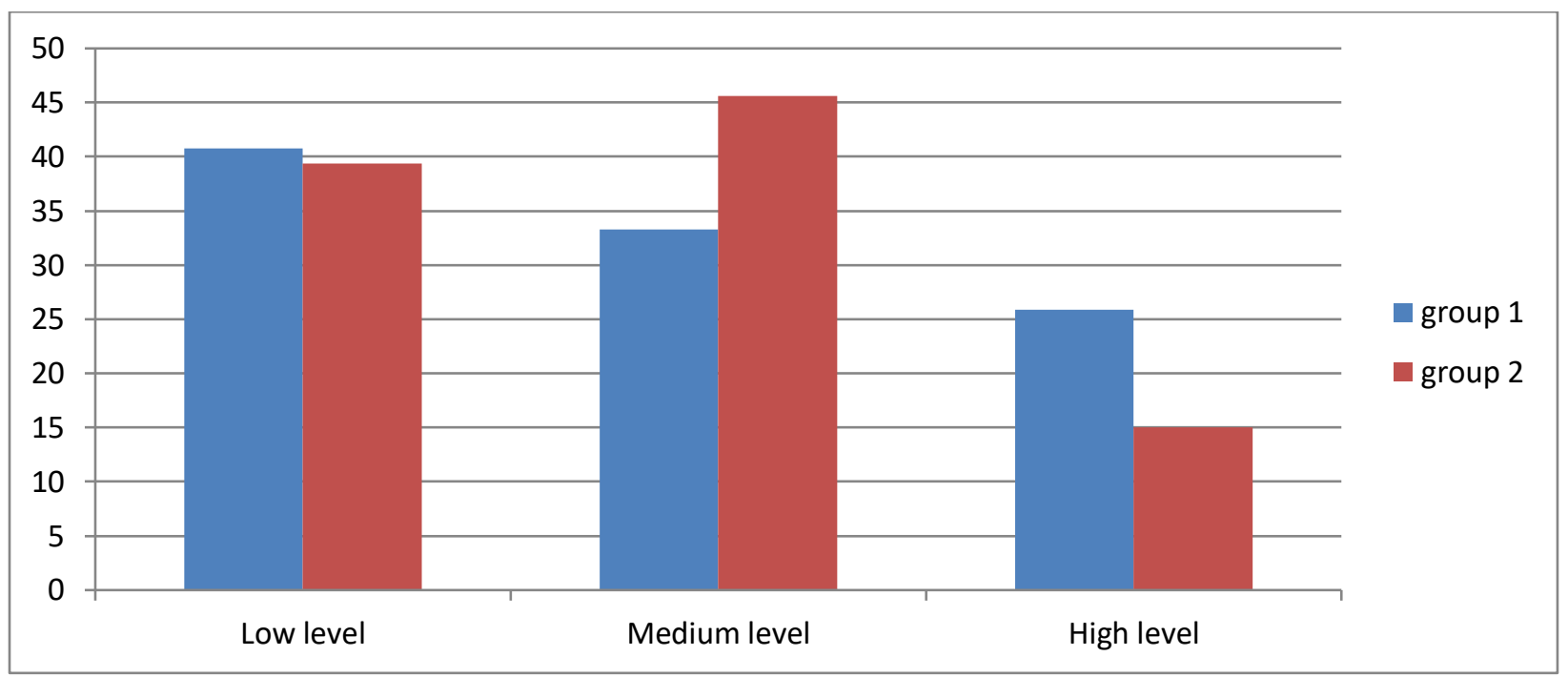

Figure 2. Students' diagnostic results on Toncheva's questionnaire to detect the level of cybercommunication addiction.

Table 1. Students' diagnostic results on Andronnikova's "Propensity for victim behavior" technique.

\begin{tabular}{lcccccc}
\hline \multirow{2}{*}{ scales $^{*}$} & \multicolumn{2}{c}{ Below the average (1-3 sten) } & \multicolumn{2}{c}{ Mean (4-7 sten) } & \multicolumn{2}{c}{ Above the average (8-10 sten) } \\
\cline { 2 - 6 } & $\mathrm{G} 1$ & $\mathrm{G} 2$ & $\mathrm{G} 1$ & $\mathrm{G} 2$ & $\mathrm{G} 1$ & $\mathrm{G} 2$ \\
\hline 1 & $25.8 \%$ & $8.8 \%$ & $63.3 \%$ & $80.7 \%$ & $13.9 \%$ & $10.5 \%$ \\
2 & $54.2 \%$ & $25.4 \%$ & $42.5 \%$ & $56.2 \%$ & $3.3 \%$ & $18.4 \%$ \\
3 & $34.2 \%$ & $50.8 \%$ & $53.3 \%$ & $42.1 \%$ & $12.5 \%$ & $7.1 \%$ \\
4 & $19.2 \%$ & 36.85 & $47.5 \%$ & $49.2 \%$ & $33.3 \%$ & $14 \%$ \\
5 & $24.2 \%$ & $28.9 \%$ & $72.5 \%$ & $48.3 \%$ & $3.3 \%$ & $22.8 \%$ \\
6 & $56.7 \%$ & $33.3 \%$ & $38.3 \%$ & $45.6 \%$ & $5 \%$ & $21.1 \%$ \\
7 & $67.2 \%$ & $36 \%$ & $22.8 \%$ & $49.1 \%$ & $12 \%$ & $14.9 \%$ \\
\hline
\end{tabular}

Note: *Scales: 1. The scale of social desirability of answers. 2. The scale of propensity for aggressive victim behavior (an aggressive type of a victim) ( $X 2 \mathrm{emp}=37.286$, the relationship between factor and effective features is statistically significant at a significance level of $p$ <.001). 3. The scale of propensity for self-damaging and self-destructive behavior (an active type of a victim) $(x 2 \mathrm{emp}=$ 42.344, the relationship between factor and effective features is statistically significant at a significance level of $p<.001)$. 4. The scale of propensity for hyper social behavior (a pro-active type of a victim). 5. The scale of propensity for dependent and helpless behavior (a passive type of a victim) $(X 2 \mathrm{emp}=25.044$, the relationship between factor and effective features is statistically significant at a significance level of $p<.001)$. 6. The scale of propensity for non-critical behavior (a non-critical type of a victim) ( $x^{2}$ emp $=37.131$, the relationship between factor and effective features is statistically significant at a significance level of $p<.001)$. 7. The scale of implemented victimization ( $x 2 \mathrm{emp}=56.932$, the relationship between factor and effective features is statistically significant at a significance level of $p<.001)$.

The results obtained indicate that $40.8 \%$ of Bulgarian students (39.4\% of Russian students, respectively) have a low level of cyber-communication addiction. It is alarming that $25.8 \%$ of the Bulgarian students and $15.5 \%$ of the Russian students showed a high level of cyber-communication addiction ( $X 2 \mathrm{emp}=23.536$, the relationship between factor and effective features is statistically significant at a significance level of $p<.001$ ). 
High levels on the scale of cyber-communication addiction indicate that students are dependent on communication in the most popular communication environment of the Internet - a social network. Students' diagnostic results on 0.0. Andronnikova's (2005) technique "Propensity for victim behavior" are presented in Table 1.

The results of the research show that the propensity for risk of $12 \%$ of the $\mathrm{G} 1$ sample and $14.9 \%$ of the G2 sample on the 7th scale of "implemented victimization" is "above the average". This means that young people, due to their internal predisposition, namely trustfulness, spontaneity, impulsiveness, and thoughtlessness, can quite often find themselves in unpleasant, sometimes life-threatening, situations on the Internet. "Below the average" indicators - $67.2 \%$ of the $\mathrm{G} 1$ sample and $36 \%$ of the $\mathrm{G} 2$ sample -show that young people do not often get into dangerous, crisis-ridden situations on the Web, preferring protective behavior. However, it is worth paying attention to the fact that there is intrinsic motivation of a person for victim behavior. In addition, we revealed credible differences at a significance level of $p<.001$ in the following indicators: "The scale of propensity for aggressive victim behavior (an aggressive type of a victim)", "The scale of propensity for selfdamaging and self-destructive behavior (an active type of a victim)", "The scale of propensity for dependent and helpless behavior (a passive type of a victim)","The scale of propensity for non-critical behavior (a noncritical type of victim)" "The scale of implemented victimization".

The results of the ascertaining stage of the research of university students in Russia and Bulgaria allow us to state that serious, systematic, substantial preventive and corrective work is needed to reduce student victimization, cyber addiction, and the formation of information security for students on the Internet. Teaching students to carefully perceive and critically evaluate information is one of the possible ways to create safe behavior on the Web, since ignorance of the rules of work and communication leads to rash, risky, frivolous actions on the Internet.

What has KFU done to solve this problem? The idea of creating a safe educational environment as a favorable social one that considers the intellectual, moral, and communicative capabilities of the students, ensuring their comfortable integration into the sociocultural and information environment and safe use of information technology in the educational process is the way to prevent and correct students' victim behavior on the Internet. The conditions are being formed for the upbringing and formation of a personality, for creating safety and satisfaction of the basic needs of all participants of the educational process, for their professional development and for the prevention of antisocial behavior.

Below are the stages of creating a safe educational environment in the framework of prevention and correction of university students' victim behavior on the Internet (Biktagirova et al., 2019):

\section{Stage 1 - Organizational}

1) Development of a regulatory framework to ensure the safe behavior of students on the Internet; the formation of a respectful attitude towards intellectual property and copyright among students, a conscious refusal to use pirated content;

2) Creation of a teaching materials database(special courses, preventive and correctional programs, videos, memos, brochures, etc.);

3) Early psychological diagnosis of victimogenic qualities and personality traits and early identification of stable psycho-emotional states of students determining their victim behavior on the Internet;

4) Drawing up a plan for the implementation of the program for security on the Internet for students. 


\section{Stage 2 - Practical}

1) Organization and implementation of a program for students' victim behavior prevention and correction;

2) Development of recommendations for teachers and students on confronting Internet risks;

3) Introduction into curriculum of special courses, such as "General Fundamentals of Victimology" and "Theory and Practice of Devictimization";

4) Creation of information repository;

5) Carrying out work with academic supervisors;

6) Holding seminars, round tables as part of educational work;

7) Strengthening the material and technical base of the university: modern computers integrated into a local network and providing constant access to the Internet; multimedia projectors compatible with laptops to demonstrate media texts in any classroom of the university; interactive whiteboards to help combine the process of demonstrating and creating media text; the presence of video cameras and cameras that allow you to capture moments of educational activity and create your own media products. A professional and responsible approach to the selection of software, a combination of licensed and freely distributed software will make it possible to create high-level media products, installation of content filters.

\section{Stage 3 - Generalizing}

1) Re-diagnosis;

2) Analysis of the results of the project in accordance with the goals and objectives;

3) Determination of prospects and ways of further development.

\section{DISCUSSION AND CONCLUSIONS}

Thus, to date there has been a significant increase in the number of cyber victims of manipulative informational impact on the Internet -the problem that is studied by cybervictimology. The subjects of cybervictimology are cyber threats, their sources, mechanisms of informational and psychological influences, causes, motives and factors of cybervictimization, psychological features of a victim identity, victim behavior on the Internet. The main goal of cyber victimization is to ensure effective informational, psychological, and pedagogical security of people on the Internet.

Victimity on the Internet is a deviation from the norms of safe behavior attributable to students' personality traits (riskiness, impulsiveness, recklessness, etc.) and the deformation of the value-motivational component of the personality (primarily, the deprivation of the need for security). Students' victim behavior on the Internet is influenced not only by personal victimity, but also by the criminal actions of cyberbullers and trolls.

Students' excessive victimity is caused by young age and corresponding lifestyle, and the fact that their daily life proceeds in the environment with increased victimogenicity. In this regard, it seems important to study the characteristics of students' victim behavior and the prevention and correction of victim behavior on the Internet among students is acquiring special social significance (Biktagirova et al., 2019). The findings of the research demonstrate that $11.7 \%$ of students from Bulgaria and $14.9 \%$ of students from Russia showed a risk appetite, including the uncontrolled one.

Considering the types of propensities for victim behavior, the Russian sample group is characterized by a proneness to aggressive, dependent, and helpless behavior. Students from Bulgaria tend to demonstrate self-damaging and self-destructive behavior as well as cyber-communication addiction. 
The safety of young people on the Internet should be guaranteed not only by way of prohibiting access to malicious resources (these requirements are fulfilled by the provider), but also by coordinated actions of law enforcement and educational institutions to form the foundations of personal information security. In the fight against dangerous and harmful information on the Web, national projects and programs of a single state are not enough; it is necessary to ensure full-scale information security for young people by interacting in an international association. The creation of a safe educational environment in a university is based on considering the intellectual, moral, and communicative capabilities of the subjects of the educational process. The current research proposes three stages of creating a safe educational environment to prevent and correct victim behavior of university students on the Internet.

A group of Russian and Bulgarian researchers plans comprehensive formative activities for the prevention and correction of students' victim behavior on the Internet and the creation of a safe information environment in universities, as well as a control experiment to verify their effectiveness.

\section{Limitation and study forward}

If the given research presents only the ascertaining stage of the experiment, the results cannot yet be discussed. We intend to continue our research. It might be necessary to increase the research sample. We plan to develop and implement a program for the prevention and correction of students' victim behavior in Russia and Bulgaria and to develop psychological and pedagogical conditions for the prevention and correction of victim forms of student behavior.

\section{ACKNOWLEDGMENTS}

The work is performed according to the Russian Government Program of Competitive Growth of Kazan Federal University.

\section{REFERENCES}

Andronnikova, O.O. (2005). Victim behavior of adolescents: factors of occurrence and prevention. Novosibirsk: Izdatel'stvo novosibirskogo gosudarstvennogo instituta - The publishing House of Novosibirsk State Institute.

Andronnikova, O.O. (2009). The main characteristics of adolescents with self-damaging victim behavior. The Herald of Tomsk State Pedagogical University, 9(87), 36-42.

Biktagirova, G.F., Valeeva, R.A., Drozdikova-Zaripova, A.R., Kalatskaya, N.N. \& Kostyunina, N.Yu. (2019). Prevention and correction of students' victim behavior on the Internet: theory and practice. Kazan: Otechestvo.

Bogacheva, T.V. (2014). Pedagogical risks of the Internet space for the health of children and adolescents and their minimization. The world of psychology, 4, 211-216.

Child Safety Online. (2019) In Russian. Retrieved from: http://www.school385.ru/vospitatelnayarabota/bezopinternet

Federal Law. (2010). Federal Law of the Russian Federation of December 29, 2010 No. 436-Ф3 «On the Protection of Children from Information harmful to their Health and Development». In Russian. Retrieved from: http://www.consultant.ru/document/cons_doc_LAW_108808/

Kostyunina, N.Yu., Latypova, L.A. \& Sirazeeva, A.F. (2018). Prevention of students' victim behavior on the internet. European Proceedings of Social \& Behavioural Sciences EpSBS, 23, 193-205. https://doi.org/10.15405/epsbs.2018.09.23 
Kowalski, R.M., Giumetti, G.W., Schroeder, A.N. \& Lattanner, M.R. (2014). Bullying in the digital age: a critical review and meta-analysis of cyberbullying research among youth. Psychol Bull, 1, 140-153. https://doi.org/10.1037/a0035618

Krapp, P. (2005). Terror and Play, or What was Hacktivism? Grey Room. MIT Press, 21, 70-93. https://doi.org/10.1162/152638105774539770

Krapp, P. (2011). Noise Channels: Glitch and Error in Digital Culture. Minneapolis: University of Minnesota Press. https://doi.org/10.5749/minnesota/9780816676248.001.0001

Makarenko, S.I. (2009). Information Security. Stavropol: SF MGGU name of M.A. Sholokhova.

Roskomsvoboda. (2020). Roskomsvoboda. In Russian. Retrieved from: https://roskomsvoboda.org/34330/

Schubert, A.M. (2019). «Readiness for Risk» technique. Schubert's «Readiness for Risk» technique. In Russian. Retrieved from: http://psycabi.net/testy/273-metodika-diagnostiki-stepeni-gotovnosti-krisku-shubert-test-sklonnosti-k-risku-shuberta

Shinkevich, M.V., Mashkin, N.A., Ishmuradova, I.I., Kolosova, V.V., \& Popova, O.V. (2020). Management of sustainable consumption of energy resources in the conditions of digital transformation of the industrial complex. International Journal of Energy Economics and Policy, 10(5), 454-460. https://doi.org/10.32479/ijeep.10202

Statistics. (2019). Statistics: modern Internet in numbers. In Russian. Retrieved from: https://www.iguides.ru/main/other/internet_statistika_sotsialnye_seti/

Taburtsa, V.A. (2016). Influence of gadgets on the psyche of a child: markers of the problem, spectrum of consequences. Scientific and methodological electronic journal «Concept», 15, 1826-1830.

Toncheva, A.V. (2012). Diagnosis of cyber-communication addiction. Internet - journal «Naukovedenie», 4, 2-3.

Tverdynin, M. (2009). Safe Internet and children: issues of counteracting the spread of illegal content on the Internet. In Russian. Retrieved from: http://www.myshared.ru/slide/240300/

\section{() $\odot \Theta \Theta$}

This work is licensed under a Attribution-NonCommercial-NoDerivatives 4.0 International (CC BY-NC-ND 4.0). 